\title{
NUTRICIÓN
}

\section{Ingesta de suplementos dietarios en estudiantes de la Universidad Iberoamericana}

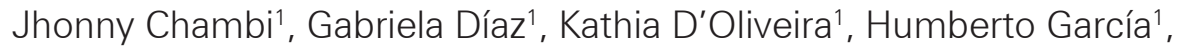 \\ Milagros Karajallo', Marlene Legal', Oscar Quintana', Milena Robledo', \\ Kathia Sánchez ${ }^{1}$, Andrea Villalba ${ }^{1}$
}

\section{Resumen}

Introducción: Los avances de la ciencia de la nutrición en las últimas décadas revelan la importancia que tiene la alimentación adecuada sobre la promoción de la salud, el bienestar físico, emocional y el rendimiento deportivo. Además del factor genético, la alimentación influye sobre el rendimiento deportivo independientemente del nivel de competición del deportista, ya sea olímpico o recreativo. La nutrición deportiva es una rama especializada aplicada a personas que practican deportes de diversa intensidad.

Es importante considerar el uso de suplementos en los deportistas basados en la evidencia de la medicina actual, de manera de obtener beneficios a partir de ellos, y así evitar riesgo de salud y dopaje.

Los suplementos dietarios son productos que acompañan la dieta de las personas a través de la incorporación de determinados nutrientes, están destinados a personas sanas, por lo tanto, no deben confundirse con medicamentos, ni tampoco consumirse con la esperanza de curar o tratar alguna dolencia. Por lo que deberá consumirse en determinadas circunstancias, cuando no es posible llevar a cabo esa dieta o debido a un estado fisiológico particular que requiera un aporte extra de algún nutriente en su dieta

Objetivo: Determinar la ingesta de suplementos dietarios en estudiantes de la UNIBE.

Material y Método: El trabajo de investigación presentó un diseño no experimental, descriptivo de corte transversal, el enfoque cuantitativo es debido a que se emplea la recolección de datos con mediciones numéricas y se utiliza el análisis estadístico con la finalidad de establecer ciertos patrones de comportamiento. Los Criterios de inclusión, los Estudiantes universitarios de las facultades de Ciencias Jurídicas, Humanidades, Salud y Empresariales, sede central. Formaron parte de la muestra la totalidad de la población accesible que

\footnotetext{
1. Universidad Iberoamericana, Paraguay.

E-mail: nutricionunibe17@gmail.com

DOI: $10.26885 /$ rcei.foro.2019.235
}

Trabajo publicado en acceso abierto bajo Licencia Creative Commons. 
cumplió con los criterios de selección previamente establecidos, en total 169 alumnos y el tipo de muestreo fue no probabilístico de conveniencia

Resultados: La muestra estuvo conformada por 169 alumnos de la UNIBE, sede central. De 169 alumnos encuestados, 58 estudiantes equivalente al 34.3\% afirma consumir algún tipo de suplemento nutricional y el $35 \%$, correspondiente a 111 alumnos, no lo hace, el $64 \%$ es del sexo femenino y el $36 \%$ corresponde al masculino, los estudiantes que consumen suplementos dietarios, el 26\% cree que el uso de SD puede ocasionar daños a su salud, mientras que el $74 \%$ afirma lo contrario. Se realizó la encuesta, en base a un instrumento, previamente elaborado con preguntas que contemplan todas las variables en estudio.

Conclusiones: Analizando los resultados de la investigación se determinó que el 34.3\% (58 estudiantes), reciben ayuda ergogénica o suplemento dietario en su alimentación, de los cuales el $64 \%$ es del sexo femenino. Las vitaminas son los SD de mayor consumo (30\%), mientras que el de menor consumo es el Própilis (1\%), una sustancia generada por las abejas, eficaz para el sistema respiratorio, protegiéndolo frente a agentes externos como bacterias y virus como los del resfriado y la gripe. Finalmente es importante recalcar que la respuesta al consumo de suplementos dietarios varía según la actividad física, las condiciones ambientales y psicológicas, la alimentación y el estado nutricional.

Palabras clave: ingesta, suplementos, estudiantes.

\section{Referencias}

Argentina. Ley $N^{\circ}$ 18284. Código Alimentario Argentino. Capítulo XVII. Artículo $N^{\circ} 1381$.

Melvin, W. Nutrición para la salud, la condición física y el deporte. https://books. google.es/books?onal\&ots=Cb655Vnilf\&sig=udvWdvHbLyMdtHPstzp_ jLIxrBs\# $v=$ onepage \& $q=$ suplemento\%20nutricional $\& f=$ false

Olivos, C., Cuevas, A., Álvarez, V., Jorquera, C. (2012). Nutrición para el entrenamiento y la competición. https://www.sciencedirect.com/ science/article/pii/S0716864012703085\#bib0005

Onzari, M. (2014). Fundamentos de Nutrición en el Deporte. Buenos Aires: Editorial El Ateneo.

Paraguay. Ley N¹119/1997, De productos para la salud y otros. Artículo 24. Decreto $N^{\circ} 3586$. 